\title{
Oncogenic features of the JMJD2A histone demethylase in breast cancer
}

\author{
WILLIAM L. BERRY ${ }^{1}$, SOOK SHIN ${ }^{1}$, STAN A. LIGHTFOOT ${ }^{2}$ and RALF JANKNECHT ${ }^{1}$ \\ Departments of ${ }^{1}$ Cell Biology and ${ }^{2}$ Pathology, University of Oklahoma Health Sciences Center, \\ Oklahoma City, OK 73104, USA
}

Received May 27, 2012; Accepted July 6, 2012

DOI: $10.3892 /$ ijo.2012.1618

\begin{abstract}
Estrogen receptor $\alpha(\mathrm{ER} \alpha)$ plays a pivotal role in the genesis of the majority of breast tumors. Consequently, endocrine therapy is now routinely utilized in the clinic for the treatment of ER $\alpha$-positive breast cancer patients. However, how ER $\alpha$ activity becomes dysregulated in breast cancer cells remains to be elucidated. The aim of this study was to show that the histone demethylase JMJD2A, also known as $\mathrm{KDM} 4 \mathrm{~A}$, is capable of forming a complex with $\mathrm{ER} \alpha$ in vivo. Moreover, wild-type JMJD2A, but not a catalytically impaired mutant, was able to strongly coactivate ER $\alpha$-mediated transcription. Consistently, the downregulation of JMJD2A in human T47D breast cancer cells led to a decreased expression of cyclin D1, a prominent ER $\alpha$ target gene and cell cycle regulator. The downregulation of JMJD2A induced a reduction in the growth of T47D cells. In addition, we found that JMJD2A is overexpressed in human breast tumors both at the mRNA and protein level. Taken together, these data indicate that the overexpression of JMJD2A may contribute to breast tumor formation by stimulating ER $\alpha$ activity and that JMJD2A may be a breast-relevant oncoprotein. As such, small molecule drugs targeting the catalytic center of JMJD2A might be useful in breast cancer adjuvant therapy.
\end{abstract}

\section{Introduction}

Tumors are characterized by a change of the transcriptome, which occurs to a large extent due to alterations in the chromatin structure. A key element of chromatin regulation is the post-translational modification of histones, including their acetylation and methylation on lysine residues. While histone acetylation is normally correlated with increased gene transcription, histone methylation is able to induce silencing or

Correspondence to: Dr Ralf Janknecht, University of Oklahoma Health Sciences Center, Department of Cell Biology, 975 NE 10th Street, BRC-1464, Oklahoma City, OK 73104, USA

E-mail: ralf-janknecht@ouhsc.edu

Key words: breast cancer, estrogen receptor, gene transcription, histone demethylase, JMJD2A activation of genes depending on which histone lysine residue is modified and whether this lysine becomes mono-, di- or trimethylated (1). A prominent family of histone lysine-modifying enzymes comprises the Jumonji C domain (JMJD) demethylases, whose dysregulation has been suggested in cancer development $(2,3)$.

One subfamily of JMJD proteins consists of JMJD2A, JMJD2B, JMJD2C and JMJD2D (4). These four JMJD2 proteins share extensive homology at their N-termini harboring the catalytic domain, however, JMJD2D is different from the other three JMJD2 proteins in that it lacks their extensive C-terminus which contains PHD and TUDOR domains involved in binding to modified histone residues $(5,6)$. In addition, whereas JMJD2A, B and C are capable of demethylating histone 1.4 on lysine 26 as well as histone 3 on lysines 9 and 36, JMJD2D is unable to demethylate the latter lysine residue (7-13). Moreover, compared to JMJD2A and JMJD2C, JMJD2B seems to be much less catalytically active $(7,10)$. Thus, the four JMJD2 family members exhibit different biochemical properties and are thought to perform distinct physiological functions.

The mRNA expression of JMJD2B, but not of JMJD2A or JMJD2C, is induced by estrogen and JMJD2B is therefore potentially important in estrogen receptor $\alpha(\mathrm{ER} \alpha)$-positive tumors. Consistently, JMJD2B is more highly expressed in $\mathrm{ER} \alpha$-positive compared to ER $\alpha$-negative human breast tumors and is required for the maximal proliferation of estrogendependent MCF7 breast cancer cells (14-16). Furthermore, only JMJD2B and JMJD2C appear to be overexpressed in medulloblastomas and their enzymatic activities may contribute to the neoplastic transformation of brain cells (17). In the present study, we focused on JMJD2A, also known as KDM4A (lysine demethylase 4A), and assessed its potential role in breast cancer.

\section{Materials and methods}

Immunohistochemistry. Tissue microarrays consisting of 12 (AccuMax A712[14]) or 20 (AccuMax A312) matching samples of human breast tumors and normal tissues were purchased from ISU Abxis. Staining with JMJD2A antibodies (Bethyl A300-861A or Abcam ab70786) was performed as described in a previous study (18) and graded by a boardcertified pathologist. 

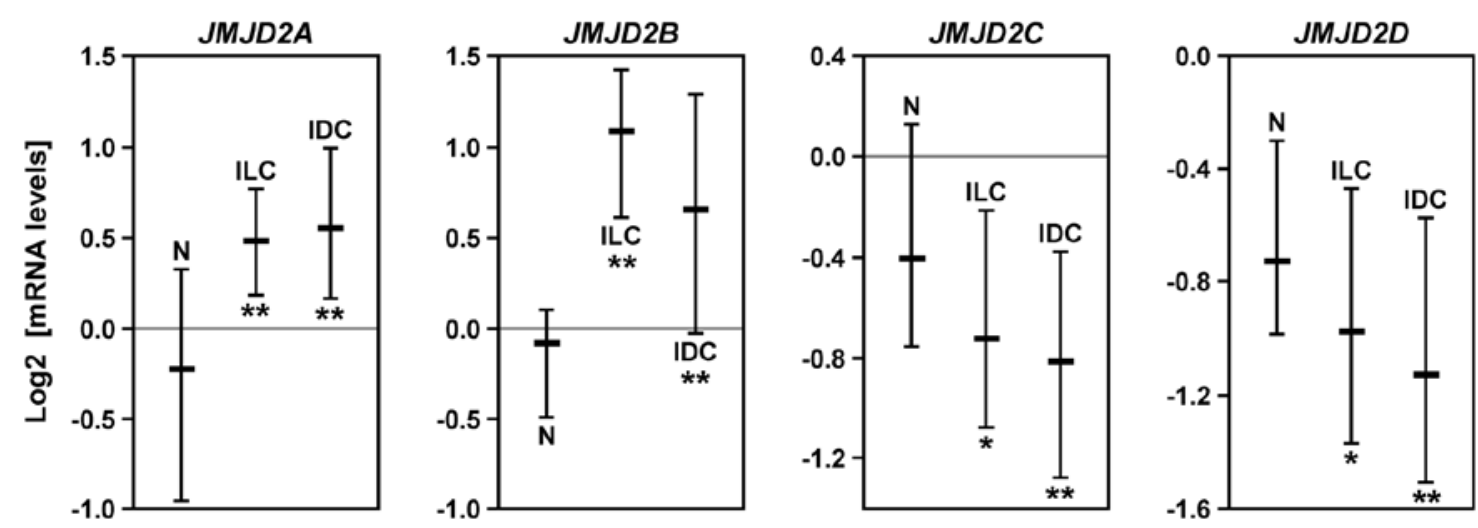

Figure 1. Expression of JMJD2 mRNAs in 61 normal (N), 36 invasive lobular breast carcinomas (ILC) and 392 invasive ductal breast carcinomas (IDC). Shown are $\log 2$-transformed mRNA levels with the median and a $25-75 \%$ percentile range. Statistical significance (Student's t-test) of difference in mRNA expression compared to normal breast tissue is indicated: " $\mathrm{p}<0.05 ;{ }^{* *} \mathrm{p}<0.0001$. Microarray data were retrieved from The Cancer Genome Atlas, National Cancer Institute, and analyzed through the Oncomine web portal (www.oncomine.org).

Coimmunoprecipitation assays. MCF7 cells were grown in the absence or presence of $1 \mathrm{nM}$ estradiol (19). Cells were lysed in $50 \mathrm{mM}$ Tris ( $\mathrm{pH} 7.4$ ), $50 \mathrm{mM} \mathrm{NaF}, 150 \mathrm{mM} \mathrm{NaCl}$, $0.5 \%$ Igepal CA-630, 0.1 mM DTT, $0.5 \mathrm{mM}$ PMSF, $0.25 \mathrm{mM}$ $\mathrm{Na}_{3} \mathrm{VO}_{4}, 10 \mu \mathrm{g} / \mathrm{ml}$ leupeptin, $2 \mu \mathrm{g} / \mathrm{ml}$ aprotinin and $1 \mu \mathrm{g} / \mathrm{ml}$ pepstatin A (20). Immunoprecipitations were performed with ER $\alpha$ antibodies (Santa Cruz Biotechnology, Inc., Santa Cruz, CA, USA; sc-543), as previously described (21). Coprecipitated JMJD2A was then detected by western blotting utilizing JMJD2A antibodies (Bethyl Laboratories, Inc., Montgomery, TX, USA; A300-861A) and enhanced chemiluminescence (22). Similarly, coimmunoprecipitation experiments with transiently transfected 293 T cells were conducted (23).

Luciferase assays. CV-1 cells were grown in 12-well plates and transiently transfected utilizing the calcium phosphate coprecipitation method (24). The reporter plasmid ERE-luc (500 ng), pSG5-ER $\alpha$ (2.5 ng), Flag-JMJD2A (500 ng) or empty vector pEV3S (500 ng), and pBluescript $\mathrm{KS}^{+}$(1500 ng) were cotransfected (25). After transfection, cells were incubated for $36 \mathrm{~h}$ in phenol red-free media containing 5\% charcoalstripped serum with or without $1 \mathrm{nM}$ estradiol. The cells were then lysed (26) and luciferase activities determined in a luminometer, as described in a previous study (27). Averages with standard errors of triplicate experiments were determined.

RNA interference. Small hairpin RNA (shRNA) directed against JMJD2A was cloned into pSIREN-RetroQ (Clontech). Sequences targeted within the human JMJD2A mRNA were 5'-GUUGAGGAUGGUCUUACCU-3' (shRNA \#3) and 5'-GGACUUAGCUUCATAACUA-3' (shRNA\#5). Retrovirus was then produced in 293T cells, as previously described (28). The resultant retrovirus was employed to infect T47D cells (29). Infected cells were selected with $2.5 \mu \mathrm{g} / \mathrm{ml}$ puromycin for three days, after which cells were lysed by boiling in Laemmli buffer (30). Protein extracts were subjected to SDS polyacrylamide gel electrophoresis, followed by western blotting (31). The following antibodies were employed for the detection of proteins: JMJD2A (Bethyl A300-861A), actin (GenScript A00730), c-Jun (Santa Cruz Biotechnology sc-45) and cyclin D1 (Cell Signaling \#2926).
Cell proliferation assay. Infected, puromycin-selected T47D cells (as mentioned above) were seeded into 96-well plates in DMEM supplemented with $10 \%$ fetal calf serum. One day after seeding, the cell number was counted for the first time (defined as day 0 ) and two days later, the cell number was counted again. The TACS MTT [3-(4,5-dimethylthiazol-2-yl)-2,5-diphenyltetrazolium bromide] kit (Trevigen Inc., Gaithersburg, MD, USA) was employed to count the cell numbers, according to the manufacturer's recommendations. Averages with standard errors of triplicate experiments were determined.

\section{Results}

Overexpression of JMJD2A in breast tumors. To study the expression pattern of JMJD2 genes in human breast tumors, publicly available microarray data retrieved from The Cancer Genome Atlas were analyzed through the Oncomine web portal (www.oncomine.org). Although JMJD2A and B mRNA expression was robustly upregulated in invasive lobular and ductal carcinomas compared to the normal breast tissue, the opposite behavior was noted for JMJD2C and D (Fig. 1). These data suggest that JMJD2A and B have different functions in breast tumors compared to JMJD2C and $\mathrm{D}$ and are consistent with the hypothesis that as with JMJD2B, JMJD2A is a potential breast-relevant oncoprotein.

To substantiate this view, we compared the degree of JMJD2A protein overexpression between normal and cancer breast tissue. To this end, we stained a total of 32 pairs of human breast tumors and matching normal breast tissues with two different JMJD2A antibodies. The two antibodies exhibited a similar staining pattern showing JMJD2A overexpression in 19 (Abcam antibody) or 20 (Bethyl antibody) tumors out of the 32 matching samples (Fig. 2). Thus, approximately $60 \%$ of all human breast tumors overexpress the JMJD2A protein.

Interaction of JMJD2A with ER $\alpha$. The majority of breast tumors are ER $\alpha$-positive and therefore endocrine therapy is applicable to most breast cancer patients (32). Thus, one mechanism by which JMJD2A is likely to contribute to breast tumor formation is through the coactivation of ER $\alpha$. A prerequisite for this would be an interaction of the two proteins. To explore 


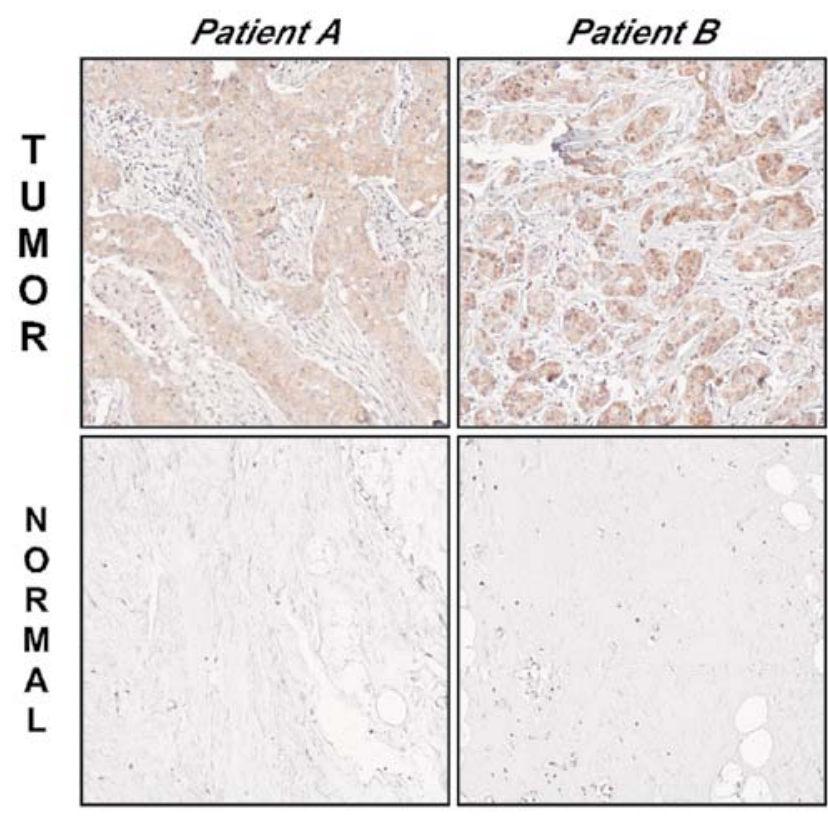

Figure 2. Overexpression of JMJD2A protein in human breast tumors. Matching normal and cancer human breast tissues were stained with JMJD2A antibody (brown color) and counterstained with hematoxylin (blue color). Two representative matched pairs of tumor and normal breast tissue stained with JMJD2A antibody from Bethyl (A300-861A) are shown.
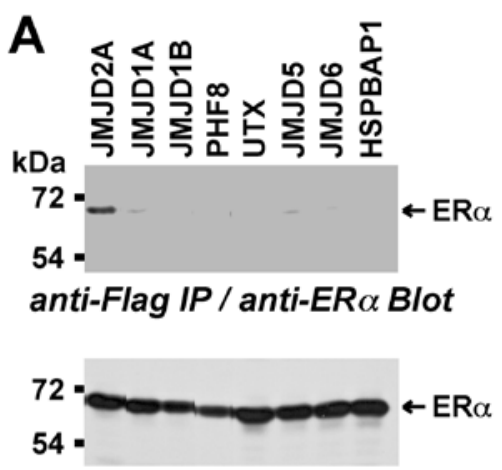

Input / anti-ER $\alpha$ Blot

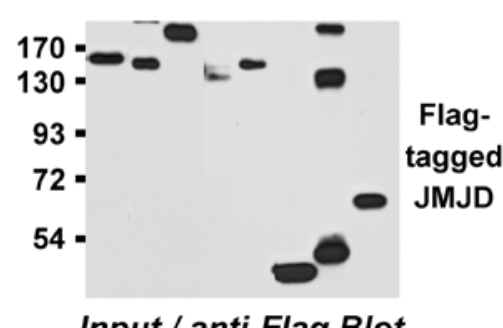

Input / anti-Flag Blot
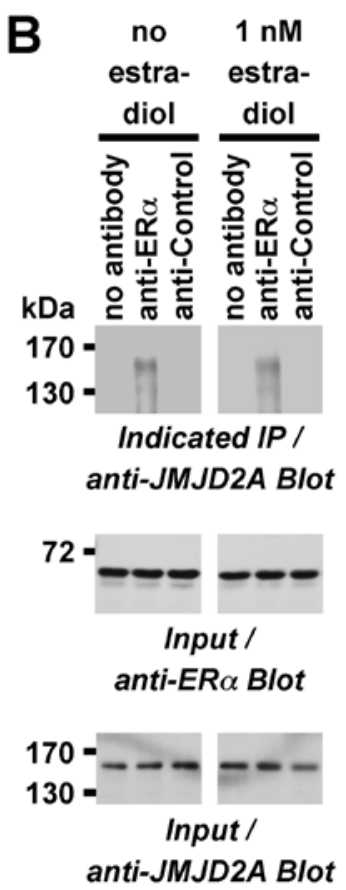

Figure 3. Interaction of JMJD2A with ER $\alpha$ is shown. (A) Indicated Flagtagged JMJD proteins were coexpressed with ER $\alpha$ in $293 \mathrm{~T}$ cells. After anti-Flag immunoprecipitation (IP), coprecipitated ER $\alpha$ was revealed by western blotting (top panel). The bottom two panels show input levels of ER $\alpha$ or Flag-tagged proteins. (B) Coimmunoprecipitation of endogenous JMJD2A with endogenous ER $\alpha$ in MCF7 breast cancer cells treated with or without $1 \mathrm{nM}$ estradiol is shown.

this, Flag-tagged JMJD2A was overexpressed with ER $\alpha$ in human 293T cells, performed anti-Flag immunoprecipitations and assayed for any coprecipitated $\mathrm{ER} \alpha$ by respective

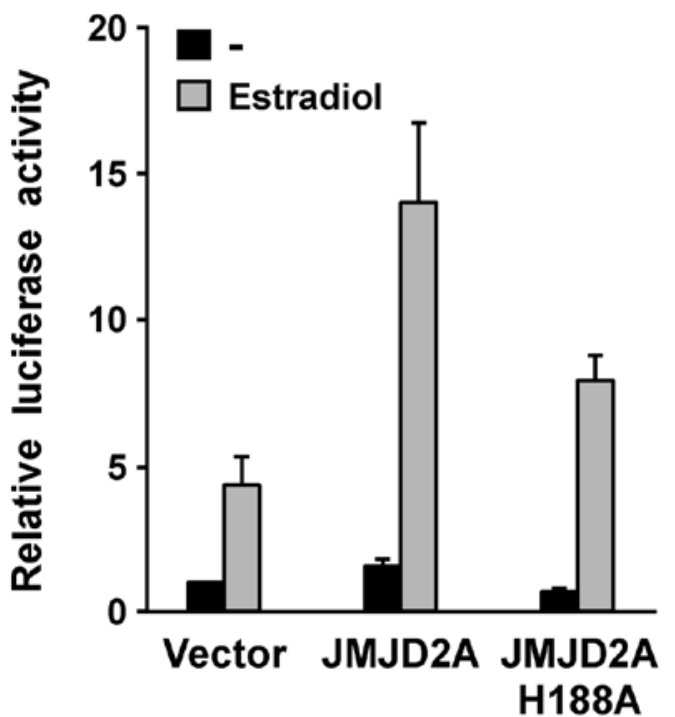

Figure 4. Activation of estrogen-dependent transcription by JMJD2A. JMJD2A (wild-type or H188A mutant) was expressed in CV-1 cells as indicated. Additionally, an ER $\alpha$-driven luciferase reporter plasmid (ERE-luc) and $\operatorname{ER} \alpha$ expression vector were cotransfected and resultant luciferase activities were determined.

western blotting. ER $\alpha$ was found to robustly coprecipitate with JMJD2A (Fig. 3A). This is not an unspecific interaction of JMJD2A with ER $\alpha$, since seven other JMJD proteins tested (JMJD1A, JMJD1B, PHF8, UTX, JMJD5, JMJD6, HSPBAP1) did not significantly form complexes with ER $\alpha$ (Fig. 3A).

To confirm that endogenous JMJD2A interacts with endogenous ER $\alpha$, human MCF7 breast cancer cells that express both proteins were examined. Furthermore, we tested whether or not such an interaction would be dependent on estradiol. To this end, ER $\alpha$ complexes were immunoprecipitated from MCF7 cells treated either with or without estradiol. Estradiol was added to all buffers utilized to immunoprecipitate ER $\alpha$ complexes from estradiol-treated cells. JMJD2A was found to coimmunoprecipitate with $\mathrm{ER} \alpha$ both in the absence and presence of estradiol (Fig. 3B), suggesting that JMJD2A forms complexes with the hormone-bound and hormone-free receptor. As a validation for specificity, JMJD2A was not precipitated with no or control antibodies (Fig. 3B). Therefore, JMJD2A forms complexes with ERa in vivo and thus potentially functions as a transcriptional cofactor of ER $\alpha$.

Stimulation of ER $\alpha$-dependent gene transcription by JMJD2A. Whether or not the interaction between JMJD2A and ER $\alpha$ is functionally relevant was assessed. To this end, we employed a luciferase reporter construct (ERE-luc) that is inducible by hormone-stimulated ER $\alpha$ (33). When ERE-luc and ER $\alpha$ were transfected together into $\mathrm{CV}-1$ cells, stimulation with estradiol led to a $\sim 5$-fold induction of luciferase activity, as expected (Fig. 4). In the absence of estradiol, JMJD2A cotransfection had only a slight impact on luciferase activity, whereas estradioldependent luciferase activity was strongly induced by JMJD2A.

We then determined whether this coactivation of ER $\alpha$ by JMJD2A is dependent on the catalytic activity of JMJD2A. To this end, we employed a mutant of JMJD2A (H188A), in which a critical histidine residue within its catalytic center was 
A
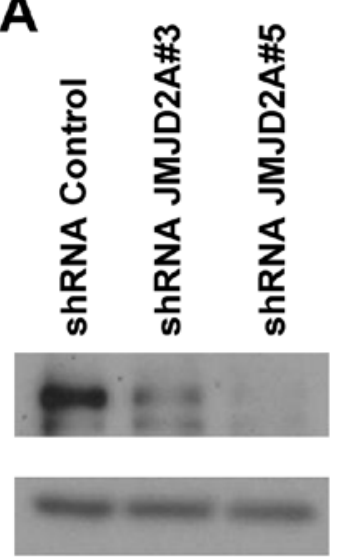

Actin
B

JMJD2A

Western Blots

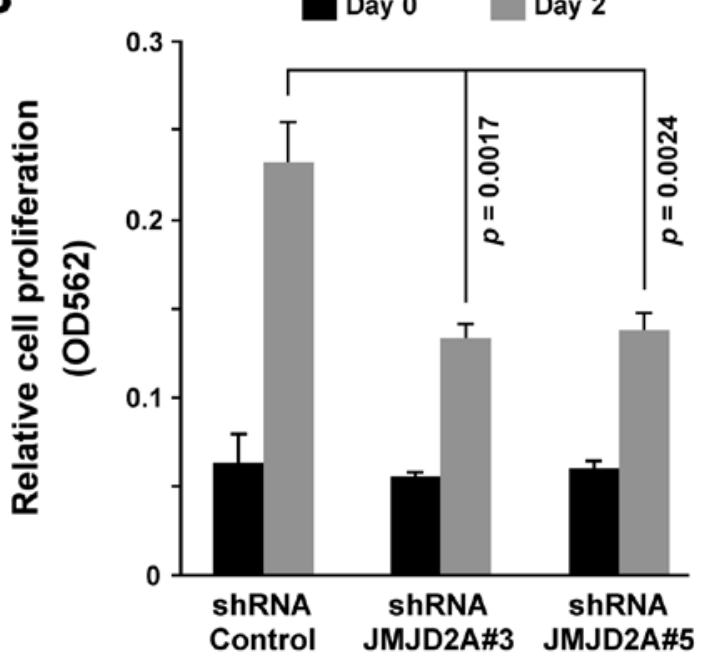

Figure 5. Impact of JMJD2A on T47D cell proliferation. (A) T47D cells were infected with retrovirus expressing a control shRNA or two different JMJD2A shRNAs (\#3 and \#5). Downregulation of JMJD2A was confirmed by western blotting. (B) Cell growth in T47D cells challenged with indicated shRNAs was monitored with an MTT assay. Statistical significance was determined with an unpaired, two-tailed t-test.

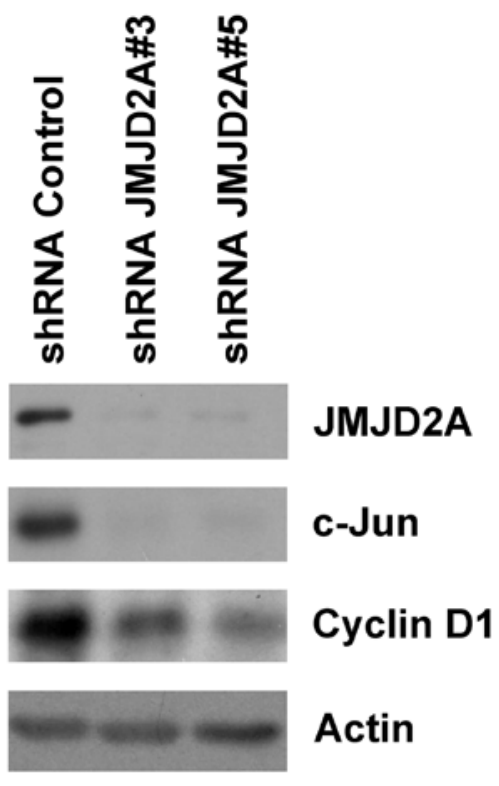

Figure 6. Downregulation of JMJD2A affects the expression of endogenous oncoproteins (c-Jun, cyclin D1) in T47D breast cancer cells.

mutated to alanine (7). Replacing wild-type JMJD2A with this H188A mutant led to a reduction of the coactivation potential of JMJD2A (Fig. 4), clearly demonstrating that the catalytic activity of JMJD2A is required for its ability to maximally stimulate estrogen-dependent gene transcription.

Impact of JMJD2A on cell growth. To assess the role of JMJD2A in breast cancer cells, JMJD2A was downregulated with two different shRNAs (\#3 and \#5) in human ER $\alpha$-positive T47D breast cancer cells. The two shRNAs effectively reduced the expression of endogenous JMJD2A protein (Fig. 5A). Of note, T47D cell growth was severely impaired by the two JMJD2A shRNAs compared to control shRNA(Fig. 5B). Thus, JMJD2A exerts a pro-proliferative role in T47D breast cancer cells.
Effects of JMJD2A downregulation on gene transcription. A target gene of ER $\alpha$ is cyclin D1 (34), which is a crucial cell cycle regulator and prominent oncogene. Thus, whether or not JMJD2A downregulation would result in decreased cyclin D1 expression in T47D cells was analyzed. Cells expressing either of the two utilized JMJD2A shRNAs exhibited a reduced cyclin D1 expression (Fig. 6). In addition, we found that another oncoprotein, c-Jun (35), became downregulated by JMJD2A ablation (Fig. 6). Thus, JMJD2A may regulate T47D cell growth through influencing the expression of at least two oncoproteins, cyclin D1 and c-Jun.

\section{Discussion}

In this study, we identified the JMJD2A histone demethylase as a novel coactivator of $\mathrm{ER} \alpha$, since i) JMJD2A formed a complex with ER $\alpha$ in vivo, ii) JMJD2A overexpression enhanced estrogen-dependent transcription, and iii) the downregulation of JMJD2A reduced transcription of a seminal ER $\alpha$ target gene, cyclin D1. Moreover, our analyses revealed that JMJD2A mRNA as well as protein are overexpressed in human breast tumors and that JMJD2A supports breast cancer cell growth. As such, JMJD2A exhibits features of an oncoprotein, whose action may be particularly relevant in ER $\alpha$-positive breast tumors.

In addition to JMJD2A, our microarray analyses showed that JMJD2B is overexpressed in invasive breast tumors, suggesting that JMJD2A and JMJD2B may perform similar functions. Consistently, it was previously reported that JMJD2B coimmunoprecipitated with ER $\alpha$ and that JMJD2B downregulation suppressed growth of the ER $\alpha$-positive breast cancer cell lines, MCF7 and T47D (14-16). Similarly, JMJD2A and B (but not JMJD2C or D) are able to perform comparable roles in the DNA damage recognition and repair pathway (36). Notably, JMJD2B downregulation had no effect on the ability of ER $\alpha$-negative MDA-MB-231 breast cancer cells to induce tumorigenesis in a nude mouse model (16), and similarly JMJD2A siRNA had a very modest impact on the proliferation of MDA-MB-231 cells 
in vitro (37). Thus, JMJD2A and B are likely to significantly promote tumorigenesis only in ER $\alpha$-positive breast tissue, which probably involves their ability to coactivate ER $\alpha$.

However, in contrast to our data showing the downregulation of JMJD2C in invasive breast tumors at the mRNA level, another report posits that JMJD2C mRNA is upregulated in breast tumors (38). One reason for this discrepancy may be the use of different breast tumor samples. Regardless, JMJD2C mRNA expression was reportedly higher in ER $\alpha$-negative compared to ER $\alpha$-positive tumors (38), which is opposite to the expression pattern of JMJD2B $(14,15)$ and is suggestive of JMJD2C not being a promoter of estrogen-dependent breast tumorigenesis.

Cyclin D1 gene transcription is induced by estradiol in breast cancer cells, which involves activation of its promoter by a complex of ER $\alpha$ and the AP-1 transcription factor $(39,40)$. Notably, cyclin D1 is frequently overexpressed in breast tumors and a respective transgenic mouse model develops breast cancer (41). Consistent with JMJD2A being an ER $\alpha$ coactivator, the downregulation of JMJD2A led to a reduced cyclin D1 expression in our study, indicating that the overexpression of JMJD2A likely contributes to breast tumor formation by inducing this oncogene.

Another oncoprotein, whose expression was reduced upon JMJD2A downregulation, was c-Jun. This transcription factor is not known to be directly regulated by $\mathrm{ER} \alpha$, however, it has important functions in breast tumors. Its overexpression in MCF7 breast cancer cells stimulated their ability to migrate, invade and form tumors in a xenograft model, while its inactivation caused cell cycle arrest $(42,43)$. Furthermore, inappropriately activated c-Jun has been found in invasive human breast tumors and c-Jun was also critical for cell invasion in ErbB2-induced mouse mammary tumors $(44,45)$. Therefore, JMJD2A overexpression may lead to the overexpression of c-Jun that is predicted to cause an invasive, aggressive phenotype of breast tumors.

Notably, JMJD2A does not only coactivate ER $\alpha$, but also the androgen receptor (46). As with estrogen receptors, the androgen receptor belongs to the nuclear hormone receptor superfamily and is crucial for the development of prostate tumors $(47,48)$. As such, one may predict that JMJD2A also contributes to the development of prostate cancer. Currently, no data supporting this hypothesis have been published, and the same holds true for JMJD2B. In addition, JMJD2A likely contributes to the development of colorectal tumors, since its downregulation impairs the proliferation and survival of colon cancer cell lines (49). In contrast to breast and prostate cancer, nuclear hormone receptors are not prime drivers of tumorigenesis in colorectal cancer. Thus, it remains to be elucidated which other pivotal DNA-binding transcription factor(s) become dysregulated by JMJD2A in colon cancer.

Originally, JMJD2A was described as a transcriptional repressor (50,51). However, published data (46) and findings of this study clearly indicate that JMJD2A also functions as a transcriptional coactivator in conjunction with the androgen receptor or ER $\alpha$. Thus, the ability of JMJD2A to regulate gene transcription may depend on which transcription factor recruits JMJD2A to a particular gene regulatory element. Mechanistically, JMJD2A particularly demethylates trimethylated lysines 9 and 36 on histone $3(2,4)$. Although the demethylation of histone 3 on lysine 9 has been associated with the activation of gene transcription (1), the function of lysine 36 methylation on histone 3 remains to be elucidated (52). Moreover, JMJD2A is capable of demethylating histone 1.4 on lysine 26 (12), and this demethylation is predicted to also induce gene transcription $(53,54)$. Thus, JMJD2A overexpression should lead to the activation of ER $\alpha$ target genes, as observed with the ERE-luc reporter construct in this study. The reduced expression of the ER $\alpha$ target gene cyclin D1 upon JMJD2A downregulation in T47D cells is consistent with the hypothesis that the function of JMJD2A is to open up chromatin, thereby facilitating estrogen-dependent transcription. Accordingly, we found that catalytically inactive JMJD2A was compromised in its ability to stimulate ER $\alpha$-mediated transcription. This latter result strongly suggests that inhibitors of JMJD2A enzymatic activity may be beneficial for the treatment of ER $\alpha$-positive breast tumors.

In conclusion, our data have identified JMJD2A as a novel bona fide ER $\alpha$ coactivator, thus deepening our understanding of estrogen-dependent transcriptional processes. In addition, the fact that JMJD2A is overexpressed in human breast tumors and required for efficient growth of breast cancer cells suggests JMJD2A as a novel potential drug target.

\section{References}

1. Kouzarides T: Chromatin modifications and their function. Cell 128: 693-705, 2007.

2. Cloos PA, Christensen J, Agger K and Helin K: Erasing the methyl mark: histone demethylases at the center of cellular differentiation and disease. Genes Dev 22: 1115-1140, 2008.

3. Chi P, Allis CD and Wang GG: Covalent histone modifications-miswritten, misinterpreted and mis-erased in human cancers. Nat Rev Cancer 10: 457-469, 2010.

4. Kooistra SM and Helin K: Molecular mechanisms and potential functions of histone demethylases. Nat Rev Mol Cell Biol 13: 297-311, 2012.

5. Klose RJ and Zhang Y: Regulation of histone methylation by demethylimination and demethylation. Nat Rev Mol Cell Biol 8: 307-318, 2007.

6. Yap KL and Zhou MM: Keeping it in the family: diverse histone recognition by conserved structural folds. Crit Rev Biochem Mol Biol 45: 488-505, 2010.

7. Whetstine JR, Nottke A, Lan F, Huarte M, Smolikov S, Chen Z Spooner E, Li E, Zhang G, Colaiacovo M and Shi Y: Reversal of histone lysine trimethylation by the JMJD2 family of histone demethylases. Cell 125: 467-481, 2006.

8. Cloos PA, Christensen J, Agger K, Maiolica A, Rappsilber J, Antal T, Hansen KH and Helin K: The putative oncogene GASC1 demethylates tri- and dimethylated lysine 9 on histone H3. Nature 442: 307-311, 2006.

9. Klose RJ, Yamane K, Bae Y, Zhang D, Erdjument-Bromage H, Tempst $\mathrm{P}$, Wong $\mathrm{J}$ and Zhang $\mathrm{Y}$ : The transcriptional repressor JHDM3A demethylates trimethyl histone $\mathrm{H} 3$ lysine 9 and lysine 36. Nature 442: 312-316, 2006.

10. Fodor BD, Kubicek S, Yonezawa M, O'Sullivan RJ, Sengupta R, Perez-Burgos L, Opravil S, Mechtler K, Schotta G and Jenuwein T: Jmjd2b antagonizes H3K9 trimethylation at pericentric heterochromatin in mammalian cells. Genes Dev 20: 1557-1562, 2006.

11. Shin S and Janknecht R: Diversity within the JMJD2 histone demethylase family. Biochem Biophys Res Commun 353: 973-977, 2007.

12. Trojer P, Zhang J, Yonezawa M, Schmidt A, Zheng H, Jenuwein T and Reinberg D: Dynamic histone H1 isotype 4 methylation and demethylation by histone lysine methyltransferase G9a/KMT1C and the Jumonji domain-containing JMJD2/KDM4 proteins. J Biol Chem 284: 8395-8405, 2009.

13. Weiss T, Hergeth S, Zeissler U, Izzo A, Tropberger P, Zee BM, Dundr M, Garcia BA, Daujat S and Schneider R: Histone H1 variant-specific lysine methylation by G9a/KMT1C and Glp1/ KMT1D. Epigenetics Chromatin 3: 7, 2010. 
14. Yang J, Jubb AM, Pike L, Buffa FM, Turley H, Baban D, Leek R, Gatter KC, Ragoussis J and Harris AL: The histone demethylase JMJD2B is regulated by estrogen receptor alpha and hypoxia, and is a key mediator of estrogen induced growth. Cancer Res 70: 6456-6466, 2010.

15. Kawazu M, Saso K, Tong KI, McQuire T, Goto K, Son DO, Wakeham A, Miyagishi M, Mak TW and Okada H: Histone demethylase JMJD2B functions as a co-factor of estrogen receptor in breast cancer proliferation and mammary gland development. PLoS One 6: e17830, 2011.

16. Shi L, Sun L, Li Q, Liang J, Yu W, Yi X, Yang X, Li Y, Han X, Zhang Y, Xuan C, Yao Z and Shang Y: Histone demethylase JMJD2B coordinates $\mathrm{H} 3 \mathrm{~K} 4 / \mathrm{H} 3 \mathrm{~K} 9$ methylation and promotes hormonally responsive breast carcinogenesis. Proc Natl Acad Sci USA 108: 7541-7546, 2011.

17. Northcott PA, Nakahara Y, Wu X, Feuk L, Ellison DW, Croul S, Mack S, Kongkham PN, Peacock J, Dubuc A, Ra YS Zilberberg K, McLeod J, Scherer SW, Sunil Rao J, Eberhart CG, Grajkowska W, Gillespie Y, Lach B, Grundy R, Pollack IF, Hamilton RL, van Meter T, Carlotti CG, Boop F, Bigner D, Gilbertson RJ, Rutka JT and Taylor MD: Multiple recurrent genetic events converge on control of histone lysine methylation in medulloblastoma. Nat Genet 41: 465-472, 2009.

18. Mooney SM, Grande JP, Salisbury JL and Janknecht R Sumoylation of p68 and p72 RNA helicases affects protein stability and transactivation potential. Biochemistry 49: 1-10, 2010.

19. Mooney SM, Goel A, D'Assoro AB, Salisbury JL and Janknecht R: Pleiotropic effects of p300-mediated acetylation on p68 and p72 RNA helicase. J Biol Chem 285: 30443-30452, 2010.

20. Shin S and Janknecht R: Concerted activation of the Mdm2 promoter by p72 RNA helicase and the coactivators p300 and P/CAF. J Cell Biochem 101: 1252-1265, 2007.

21. Knebel J, De Haro L and Janknecht R: Repression of transcription by TSGA/Jmjd1a, a novel interaction partner of the ETS protein ER71. J Cell Biochem 99: 319-329, 2006.

22. Papoutsopoulou S and Janknecht R: Phosphorylation of ETS transcription factor ER81 in a complex with its coactivators CREB-binding protein and p300. Mol Cell Biol 20: 7300-7310, 2000

23. Kim TD, Shin S and Janknecht R: Repression of Smad3 activity by histone demethylase SMCX/JARID1C. Biochem Biophys Res Commun 366: 563-567, 2008.

24. Dowdy SC, Mariani A and Janknecht R: HER2/Neu- and TAK1mediated up-regulation of the transforming growth factor beta inhibitor Smad7 via the ETS protein ER81. J Biol Chem 278 44377-44384, 2003.

25. De Haro L and Janknecht R: Cloning of the murine ER71 gene (Etsrp71) and initial characterization of its promoter. Genomics 85: 493-502, 2005

26. Wu J and Janknecht R: Regulation of the ETS transcription factor ER81 by the $90-\mathrm{kDa}$ ribosomal S6 kinase 1 and protein kinase A. J Biol Chem 277: 42669-42679, 2002.

27. Goel A and Janknecht R: Acetylation-mediated transcriptional activation of the ETS protein ER 81 by p300, P/CAF, and HER2/ Neu. Mol Cell Biol 23: 6243-6254, 2003.

28. Shin S, Rossow KL, Grande JP and Janknecht R: Involvement of RNA helicases p68 and p72 in colon cancer. Cancer Res 67: 7572-7578, 2007.

29. Kim J, Shin S, Subramaniam M, Bruinsma E, Kim TD, Hawse JR Spelsberg TC and Janknecht R: Histone demethylase JARID1B/ KDM5B is a corepressor of TIEG1/KLF10. Biochem Biophys Res Commun 401: 412-416, 2010.

30. Kim TD, Oh S, Shin S and Janknecht R: Regulation of tumor suppressor p53 and HCT116 cell physiology by histone demethylase JMJD2D/KDM4D. PLoS One 7: e34618, 2012.

31. Shin S, Kim TD, Jin F, van Deursen JM, Dehm SM, Tindall DJ, Grande JP, Munz JM, Vasmatzis G and Janknecht R: Induction of prostatic intraepithelial neoplasia and modulation of androgen receptor by ETS variant 1/ETS-related protein 81. Cancer Res 69: 8102-8110, 2009

32. Normanno N, Di Maio M, De Maio E, De Luca A, de Matteis A, Giordano A and Perrone F: Mechanisms of endocrine resistance and novel therapeutic strategies in breast cancer. Endocr Relat Cancer 12: 721-747, 2005

33. Paech K, Webb P, Kuiper GG, Nilsson S, Gustafsson J, Kushner PJ and Scanlan TS: Differential ligand activation of estrogen receptors ERalpha and ERbeta at AP1 sites. Science 277: 1508-1510, 1997.

34. Carroll JS and Brown M: Estrogen receptor target gene: an evolving concept. Mol Endocrinol 20: 1707-1714, 2006.
35. Shaulian E and Karin M: AP-1 as a regulator of cell life and death. Nat Cell Biol 4: E131-E136, 2002.

36. Mallette FA, Mattiroli F, Cui G, Young LC, Hendzel MJ, Mer G, Sixma TK and Richard S: RNF8- and RNF168-dependent degradation of KDM4A/JMJD2A triggers 53BP1 recruitment to DNA damage sites. EMBO J 31: 1865-1878, 2012

37. Li BX, Zhang MC, Luo CL, Yang P, Li H, Xu HM, Xu HF, Shen YW, Xue AM and Zhao ZQ: Effects of RNA interferencemediated gene silencing of JMJD2A on human breast cancer cell line MDA-MB-231 in vitro. J Exp Clin Cancer Res 30: 90, 2011.

38. Liu G, Bollig-Fischer A, Kreike B, van de Vijver MJ, Abrams J, Ethier SP and Yang ZQ: Genomic amplification and oncogenic properties of the GASC1 histone demethylase gene in breast cancer. Oncogene 28: 4491-4500, 2009.

39. Altucci L, Addeo R, Cicatiello L, Dauvois S, Parker MG, Truss M, Beato M, Sica V, Bresciani F and Weisz A: 17beta-Estradiol induces cyclin D1 gene transcription, p36D1-p34cdk4 complex activation and $\mathrm{p} 105 \mathrm{Rb}$ phosphorylation during mitogenic stimulation of $\mathrm{G}(1)$-arrested human breast cancer cells. Oncogene 12 : 2315-2324, 1996.

40. Cicatiello L, Addeo R, Sasso A, Altucci L, Petrizzi VB, Borgo R, Cancemi M, Caporali S, Caristi S, Scafoglio C, Teti D, Bresciani F, Perillo B and Weisz A: Estrogens and progesterone promote persistent CCND1 gene activation during G1 by inducing transcriptional derepression via c-Jun/c-Fos/estrogen receptor (progesterone receptor) complex assembly to a distal regulatory element and recruitment of cyclin D1 to its own gene promoter. Mol Cell Biol 24: 7260-7274, 2004

41. Velasco-Velazquez MA, Li Z, Casimiro M, Loro E, Homsi N and Pestell RG: Examining the role of cyclin D1 in breast cancer. Future Oncol 7: 753-765, 2011.

42. Smith LM, Wise SC, Hendricks DT, Sabichi AL, Bos T, Reddy P, Brown PH and Birrer MJ: cJun overexpression in MCF-7 breast cancer cells produces a tumorigenic, invasive and hormone resistant phenotype. Oncogene 18: 6063-6070, 1999.

43. Liu Y, Lu C, Shen Q, Munoz-Medellin D, Kim H and Brown PH: AP-1 blockade in breast cancer cells causes cell cycle arrest by suppressing G1 cyclin expression and reducing cyclin-dependent kinase activity. Oncogene 23: 8238-8246, 2004.

44. Vleugel MM, Greijer AE, Bos R, van der Wall E and van Diest PJ c-Jun activation is associated with proliferation and angiogenesis in invasive breast cancer. Hum Pathol 37: 668-674, 2006.

45. Jiao X, Katiyar S, Willmarth NE, Liu M, Ma X, Flomenberg N, Lisanti MP and Pestell RG: c-Jun induces mammary epithelial cellular invasion and breast cancer stem cell expansion. J Biol Chem 285: 8218-8226, 2010.

46. Shin S and Janknecht R: Activation of androgen receptor by histone demethylases JMJD2A and JMJD2D. Biochem Biophys Res Commun 359: 742-746, 2007.

47. Pienta KJ and Bradley D: Mechanisms underlying the development of androgen-independent prostate cancer. Clin Cancer Res 12: $1665-1671,2006$

48. Attard G, Cooper CS and de Bono JS: Steroid hormone receptors in prostate cancer: a hard habit to break? Cancer Cell 16: 458-462, 2009.

49. Kim TD, Shin S, Berry WL, Oh S and Janknecht R: The JMJD2A demethylase regulates apoptosis and proliferation in colon cancer cells. J Cell Biochem 113: 1368-1376, 2012.

50. Gray SG, Iglesias AH, Lizcano F, Villanueva R, Camelo S, Jingu H, Teh BT, Koibuchi N, Chin WW, Kokkotou E and Dangond F: Functional characterization of JMJD2A, a histone deacetylase- and retinoblastoma-binding protein. J Biol Chem 280: 28507-28518, 2005

51. Zhang D, Yoon HG and Wong J: JMJD2A is a novel N-CoRinteracting protein and is involved in repression of the human transcription factor achaete scute-like homologue 2 (ASCL2) Hash2). Mol Cell Biol 25: 6404-6414, 2005.

52. Wagner EJ and Carpenter PB: Understanding the language of Lys36 methylation at histone H3. Nat Rev Mol Cell Biol 13: 115-126, 2012.

53. Parseghian MH, Newcomb RL, Winokur ST and Hamkalo BA: The distribution of somatic H1 subtypes is non-random on active vs. inactive chromatin: distribution in human fetal fibroblasts. Chromosome Res 8: 405-424, 2000.

54. Daujat S, Zeissler U, Waldmann T, Happel N and Schneider R: HP1 binds specifically to Lys26-methylated histone H1.4, whereas simultaneous Ser27 phosphorylation blocks HP1 binding. J Biol Chem 280: 38090-38095, 2005. 